\title{
Study the Effect of Mobile (Cell Phone) on the Heart
}

\section{Electricity}

\author{
Dawser Hussain \\ Asst. Lecturer Dept. Physics, \\ College of Science for women, \\ Baghdad University, Iraq
}

\author{
Alyaa H. Ali \\ Asst. Professor Dept. Physics, \\ College of Science for women, \\ Baghdad University, Iraq \\ Aya Juma \\ Dept. Physics, \\ College of Science for women, \\ Baghdad University, Iraq
}

\author{
Sabah N. Mazhir \\ Asst. Professor Dept. Physics, \\ College of Science for women, \\ Baghdad University, Iraq
}

\begin{abstract}
Electrical and electronic devices, wireless cellular telephones and other mobile personal communication services are the fastest growing field in the world. However, there is uncertainty about the health effects of Radio Frequency (RF). The main aim of the present work is to study the effect of cell phone on human health and especially on a heart rate by exposing a human to the radiation emitted from cell phone (EMF) and registering an ECG to the heart at different exposure times.
\end{abstract}

\section{Keywords}

Cell Phone, ECG, EMF, Electromagnetic Radiation.

\section{INTRODUCTION}

During recent years, there has been an increase in the use of telecommunication devices, which has become an easy means of communication. During the last decade the use of mobiles has become more conspicuous. Thus, has led to construction of transmission towers in large numbers, both in the urban, as well as in rural areas including other sparsely populated areas. Many attempts are made to investigate the effect of mobile phones (MP) on human health For instance, the effect of MP (on reproductive system, central nervous system, human auditory brainstem, cardiovascular system(CVS), cognitive functions and carcinogenesis etc.) [1].Electromagnetic radiation is a form of energy exhibiting wave-like behavior as it travels through space. Electromagnetic radiation has both electric and magnetic field components, which oscillate in phase perpendicular to each other and perpendicular to the direction of energy propagation [2].

Although the amount of electromagnetic energy due to cell phones is quite small in comparison to other radiofrequency sources, the increased use of wireless mobile phones worldwide (3.8 billion mobile users) has focused interest on its possible side effects, and the potential health impacts [3]. Therefore, most countries consider the radiofrequency (RF) spectrum to be the exclusive property of the state. In the 1980s, the RF spectrum was only used for radio and television broadcasting. While, nowadays the use of RF includes mobile phones, wireless computers, and many other wireless devices. The RF spectrum is divided into different frequency bands, each of which has specific applications [4].The potential health risk of the electromagnetic fields which are emitted by mobile phones (MP) is of considerable public interest [5]. The time and frequency domain measures of the HRV (Heart
Rate Variability) have provided prognostic information and they have also made it possible to perform non-invasive studies on the significance of the changes in the regulation of heart rate behavior. Electromagnetic fields which are emitted by cellular phones interfere with the work of cardiac pacemakers and other implantable medical devices $[6,7]$. Heart rate is defined as the measure of heart beats per unit time, typically expressed as beats per minute (Bpm). Heart rate measurements are used by medical professionals to assist in both diagnosis and tracking of medical conditions as well as monitoring fitness levels. HRV is a reliable marker for many physiological factors that modulate the normal rhythm of the heart. Furthermore, it is a powerful means of observing the interplay between the sympathetic and parasympathetic nervous systems [8].

The World Health Organization (WHO) has acknowledged that electromagnetic (EM) fields influence the human environment.. However, the WHO denies that EM fields, emitted from mobile phones (MPs) pose a health threat to human individuals, nevertheless, this organization acknowledges that there is a public concern about this issue [9] and [10].

\section{Materials and Method}

To achieve the aim of this paper, some materials are used such as ECG device which is a part of medical physics lab instruments, mobile phone of type Nokia 200, human bed, watch to accurate the measurement time (exposure time), thermometer to measure temperature of the volunteers, gel for ECG connection. The volunteers are (13) human, female, of Age $34-38$ years old and weight $55-70 \mathrm{Kg}$, married, and children, with no acute diseases. A simple physical examination was done to them to ensure that they don't have heart disease. First, the volunteers asked to take of her metal accessories, such as watch ...etc. Then, normal measurements to her ECG have been done and time of exposure will be Zero in this moment, this process is necessary to compare the data. After that, the sample receives a call and the phone was switched on behind her and a time of exposure was measured as $(5,10,15,20,22,30,35 \mathrm{~min})$. and at the end of each, an ECG was recorded. Also, the volunteers temperature was measured. the results obtained are shown in tables $(1,2,3)$.

\section{Result and Discussion}

The wide uses of mobile technology have often raised the question about if there are health implications for human. In fact, there are conflicting reports relating to possible health 
effects from mobile phones and base stations. From the results as the ECG recorded, it was noted that there is a random increase in the average heart rate of the volunteers; it increased from $75-103 \mathrm{bpm}$. Also, there is a random change in PR interval, and a decrease in QT wave. the $\mathrm{P}$ wave dispersion shows atria electrical activity, it is a noninvasive indicator that enables the calculation of atria fibrillation risk on the 12-lead surface ECG. Increased QT and QTD on the surface ECG reflect different aspects of abnormal ventricular re-polarization. An increase in the volunteer's temperature was noted. This is because of that a certain amount of energy from radiation is absorbed by the body and is converted to heat. This is called thermal effect. this raises public concern about the possible health effects of human exposure to electromagnetic energy. In addition to all of that, the Rhythm of the heart was irregular during the exposure. Tables $(1,2,3$ ) shows all these results.

Table 1. The variability of HR with time.

\begin{tabular}{|c|c|c|}
\hline $\begin{array}{c}\text { Exposure } \\
\text { Time (min) }\end{array}$ & $\begin{array}{c}\text { Heart } \\
\text { rate } \\
\text { (bpm) }\end{array}$ & $\begin{array}{c}\text { Heart rate in } \\
\text { lead 2 } \\
\text { (bpm) }\end{array}$ \\
\hline Normal (0) & 76 & 75 \\
\hline 5 & 76 & 78 \\
\hline 10 & 77 & 79 \\
\hline 15 & 86 & 84 \\
\hline 20 & 98 & 85 \\
\hline 22 & 96 & 94 \\
\hline 30 & 93 & 95 \\
\hline 35 & 90 & 103 \\
\hline
\end{tabular}

Table (2). The variability of PR interval, $P$ wave and $Q R S$ with time.

\begin{tabular}{|c|c|c|c|}
\hline $\begin{array}{c}\text { Exposure } \\
\text { Time (min) }\end{array}$ & $\begin{array}{c}\text { PR } \\
\text { interval } \\
(\mathbf{m s})\end{array}$ & $\begin{array}{c}\text { P wave } \\
(\mathbf{m s})\end{array}$ & $\begin{array}{c}\text { QRS } \\
(\mathbf{m s})\end{array}$ \\
\hline Normal (0) & 146 & 101 & 83 \\
\hline 5 & 149 & 101 & 84 \\
\hline 10 & 150 & 101 & 85 \\
\hline 15 & 155 & 102 & 83 \\
\hline 20 & 169 & 103 & 81 \\
\hline 22 & 167 & 106 & 82 \\
\hline 30 & 163 & 105 & 81 \\
\hline 35 & 169 & 104 & 81 \\
\hline
\end{tabular}

Table (3). The variability of QT, $T$ waves and human body temperature with time.

\begin{tabular}{|c|c|c|c|c|}
\hline $\begin{array}{c}\text { Exposure } \\
\text { Time (min) }\end{array}$ & $\begin{array}{c}\text { QT int. } \\
(\mathrm{ms})\end{array}$ & $\begin{array}{c}\text { T wave } \\
(\mathrm{ms})\end{array}$ & $\begin{array}{c}\text { Average } \\
\text { Temp. }\end{array}$ & Rhythum \\
\hline Normal (0) & 166 & 117 & 35 & irregular \\
\hline 5 & 163 & 121 & 35.24 & irregular \\
\hline 10 & 164 & 116 & 35.6 & irregular \\
\hline 15 & 201 & 123 & 36 & irregular \\
\hline 20 & 336 & 142 & 36.22 & irregular \\
\hline 22 & 330 & 143 & 36.41 & irregular \\
\hline 30 & 141 & 329 & 37 & irregular \\
\hline 35 & 155 & 141 & 37.53 & irregular \\
\hline
\end{tabular}

\section{Conclusion}

From results, we can conclude that, cell phone is not a safe device, so, we must use it as less as possible, and in necessary situations. Keeping in mind, don't put it behind heart or ear for long receiving call time, since it effect on human body temperature, as a result the temperature has been increased so the mobile effect on human rhythm, heart rate...etc. Note that The number of cases included in the study is relatively low. 
International Journal of Applied Information Systems (IJAIS) - ISSN : 2249-0868

Foundation of Computer Science FCS, New York, USA

Volume 7-No. 4, June 2014 - www.ijais.org

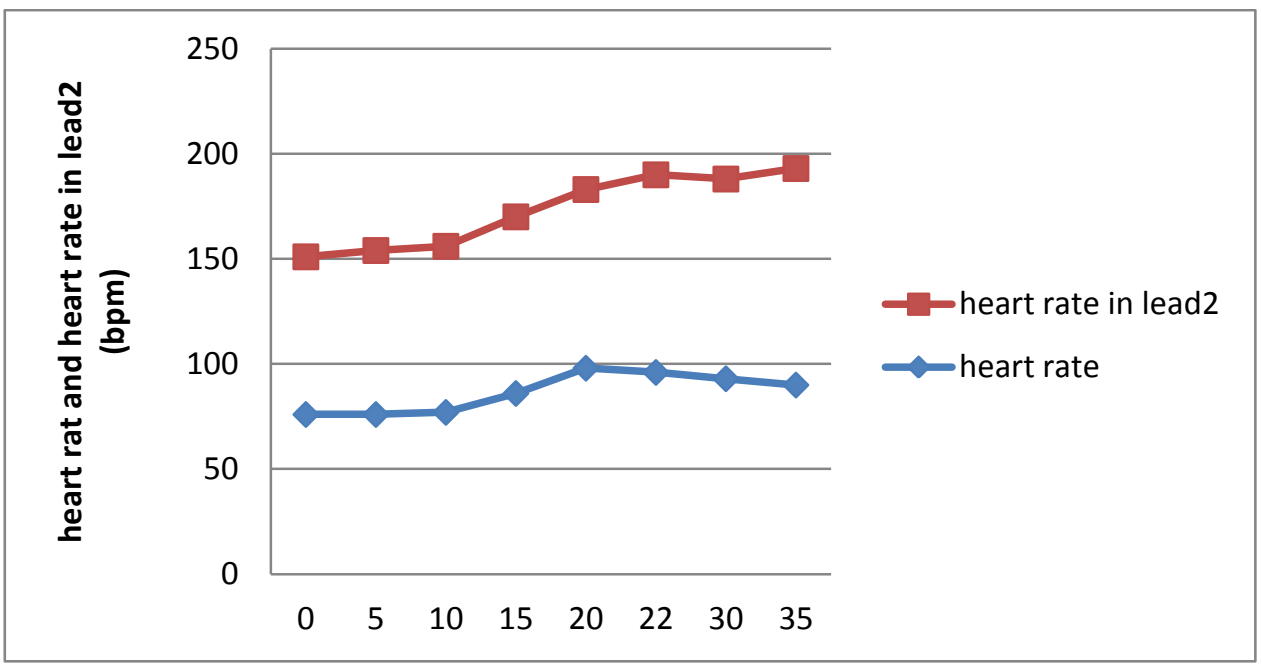

Fig 1:Behavior of Heart Rate Vs Time of Exposure

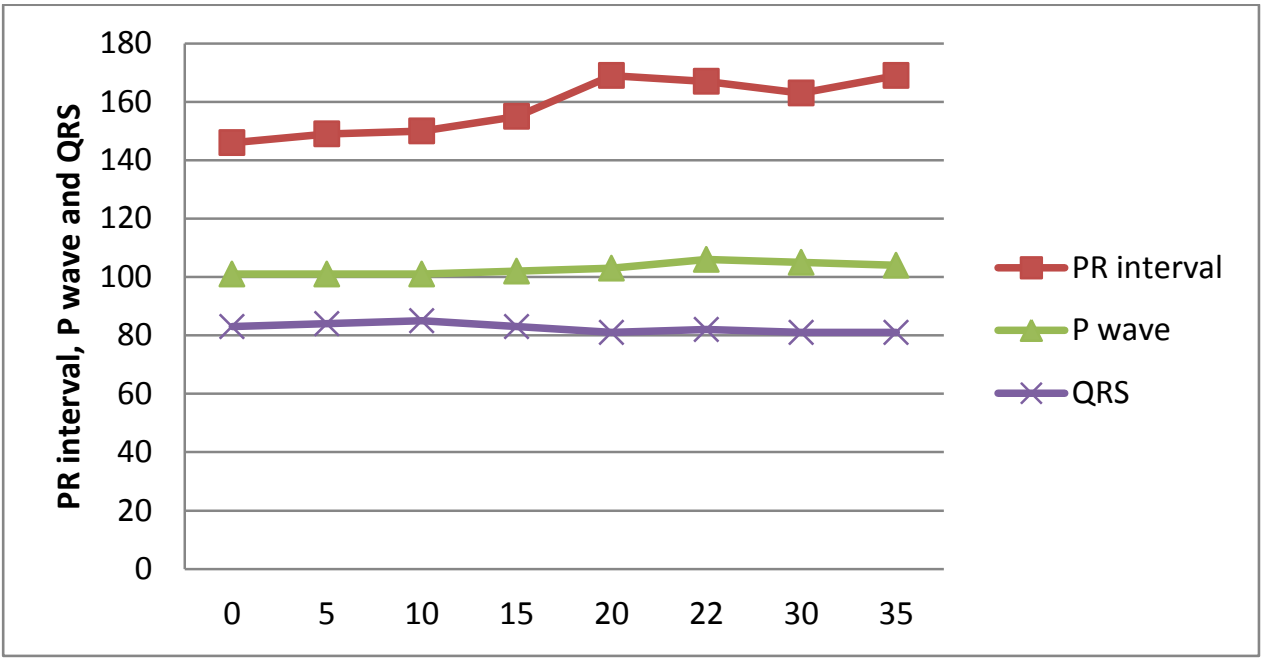

Fig 2:Behavior of PR interval, wave and QPS Vs Time of Exposure

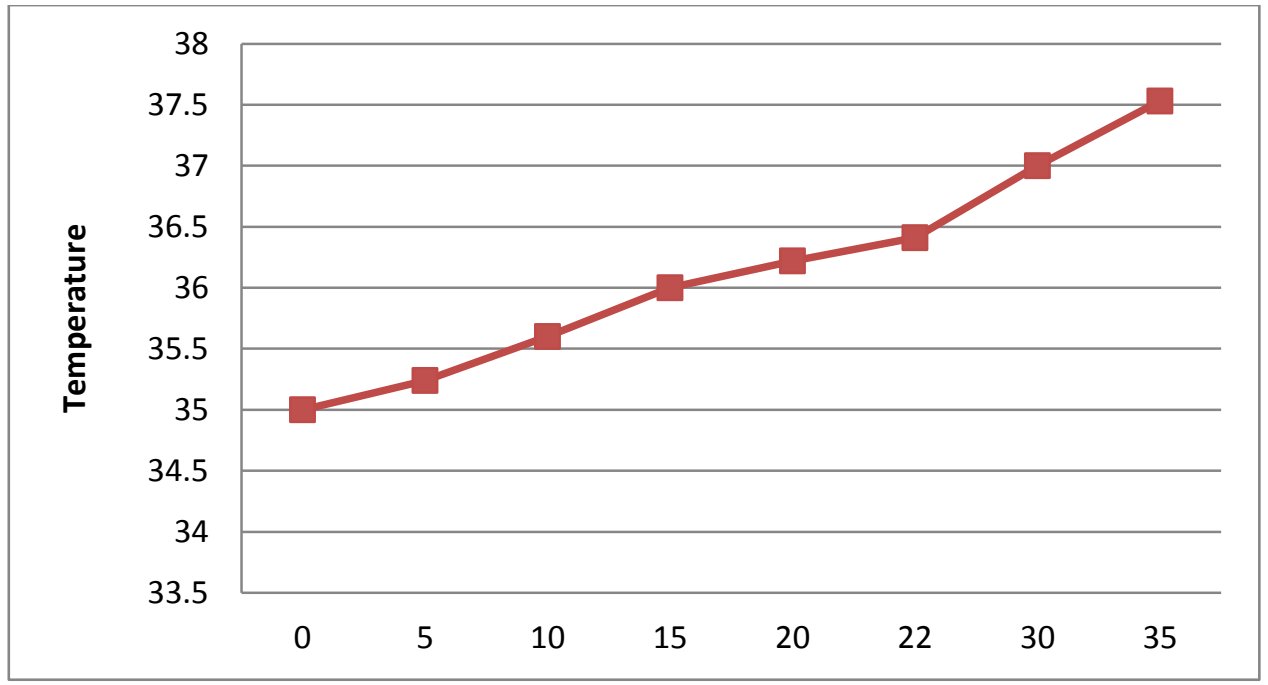

Fig 3:Behavior Temperature Vs Time of Exposure 


\section{ACKNOWLEDGMENTS}

Our thanks to the experts who have contributed towards development of the template.

\section{REFERENCES}

[1] Ali. T., Huseyin G., Serhan O., Ana do., 2009. The cardiac effects of a mobile phone positioned closest to the heart,;2009 , 9: 380-4.

[2] Aruna.T, Manoj, Duhan1, and Dinesh, B.. 2011 Effect of Mobile phone Radiation on Brain Activity GSM VS CDMA.( April 2011), IJSTM Vol. 2, Issue 2.

[3] Fatma A. Mohamed, Azza A. Ahmed, *Bataa M.A. ElKafoury and Noha N.2011.Study of the Cardiovascular Effects of Exposure to Electromagnetic Field, Lasheen Life Science Journal, Volume 8, Issue 1.

[4] John W., Hugh S. Tayloro, Nancy Alderman, Linda W., Jane M. Bradley, and Susan Addiss, 2012, Cellphone: technology, Exposures, Health Effects, 2012 Environment \& Human Health, Inc.page: 12.

[5] Bhagyalakshmi K., Venkappa S. Mantur, Nayanatara A. Kumar, Sheila Ramesh Pai 2012, A Pilot Study on Long Term Effects of Mobile Phone Usage on Heart Rate Variability in Healthy Young Adult Males, Journal of
Clinical and Diagnostic Research. 2012 May (Suppl-1), Vol-6(3):346-349.

[6] Altamura G, Toscano S, Gentilucci G, Ammirati F.1997. Influence of digital and analogue cellular telephones on implanted pacemakers. EurHeart 18:1632-41.

[7] Barbaro V, Bartolini P, Donato A, Militello C.1999. Electromagnetic interference of analog cellular telephones with pacemakers: in vitro and in vivo studies. Pace 22: 626-34.

[8] Acharya UR, Joseph KP, Kannathal N, Lim CH, Suri JS. 2006. Heart rate variability:A review, Med BiolEngComput44(12):1031-1051.

[9] Oliver F., U. Rajendra Acharya, Myagmarbayar, AR Nergui, Dhanjoo N Ghista, Subhagata, Chattopadhyay, Paul Joseph, ThajudinAhamed_and Dorithy , 2011,Tay Effects of Mobile Phone Radiation on Cardiac Health, Oliver Faust, Journal of Mechanics in Medicine and Biology Vol. 11, No. 5 (2011) 1241-1253.

[10] Alyaa, H. Ali, Loay.A Georg, Laith Al-ani, 2011 Texture analysis using Spatial Gray Level Dependence Matrix and the Logical Operators for Brodatz Images, Journal of Baghdad for Science, May,2011 